\title{
Medical Image of the Week: Superior Sulcus Tumor with Neural Invasion
}

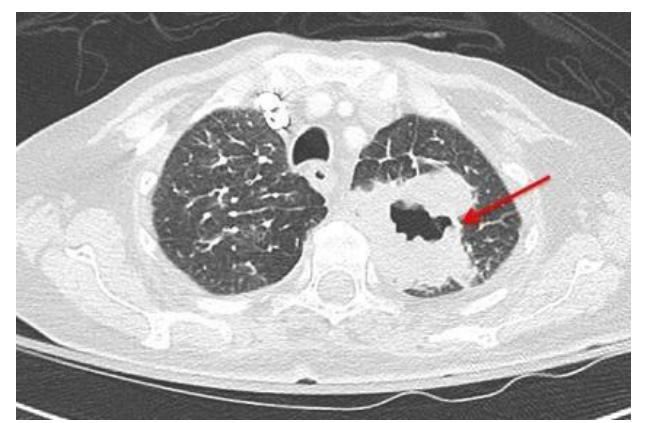

Figure 1. Computed tomography of the chest (axial image) shows a large left upper lobe cavitary mass (red arrow), consistent with known squamous cell carcinoma.

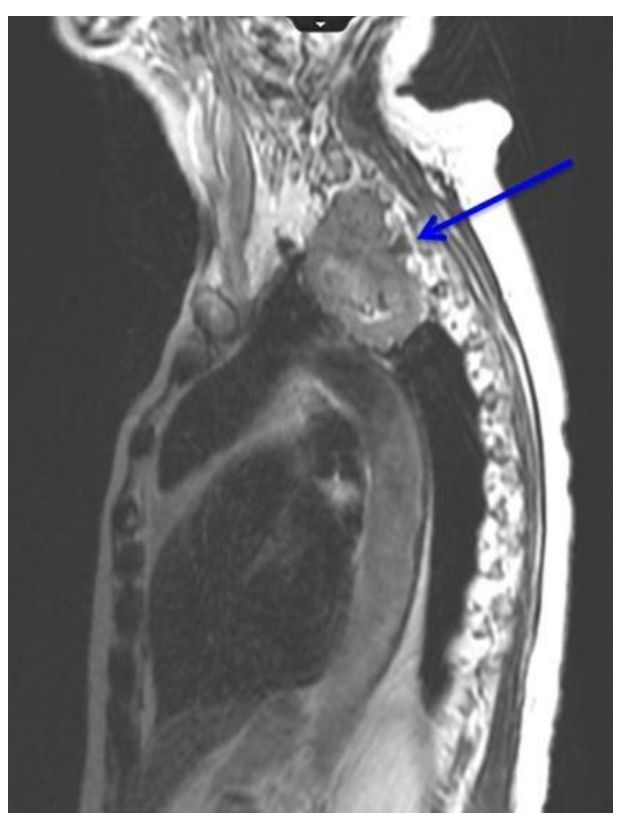

Figure 2. MRI of cervical and thoracic spine (sagittal image) reveals the mass abuts the spinal column with tumor invasion through the neural foramen at C7-T1 and T1-T2 (blue arrow).

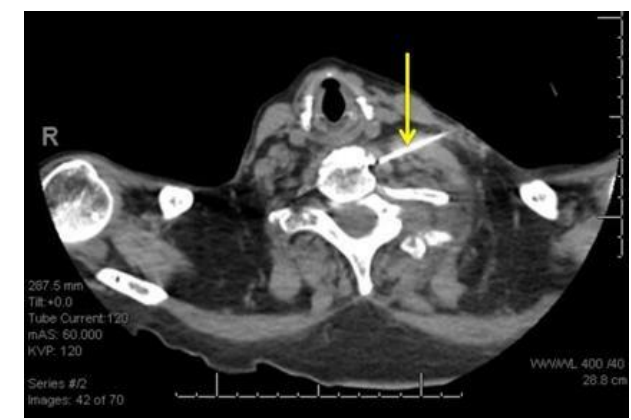

Figure 3. A 22-guage needle is advanced with its tip anterior to the longus coli muscle at the level of C6 (yellow arrow). Ethanol solution was injected into this space. 
A 78-year-old woman with left upper lobe squamous cell carcinoma presented with severe left arm and upper posterior chest pain. The pain was described as a severe burning sensation with "pins and needles", and there was loss of motor function in the arm. This neuropathic pain was refractory to escalating doses of opioids and gabapentin. She was receiving chemotherapy with paclitaxel and carboplatin and completed five radiation treatments. On physical examination, there was atrophy of the left forearm and hand muscles. No evidence of Horner's syndrome was noted.

A CT of the chest with contrast (Figure 1) showed a $5.8 \mathrm{~cm}$ apical segment left upper lobe cavitary mass consistent with a superior sulcus tumor and concomitant pulmonary embolism. An MRI of the cervical and thoracic spine (Figure 2) showed a large apical necrotic tumor abutting the upper thoracic spine with invasion of the neural foramina at C7-T1, T1-T2, and T2-T3, consistent with invasion into the brachial plexus.

In an attempt to improve her symptoms, the interventional radiologist performed a left stellate ganglion block with $1 \%$ lidocaine and $0.25 \%$ bupivacaine (Figure 3 ). There was minimal initial improvement so a repeat block was done three days later with notable reduction in arm pain. For a permanent block, a stellate ganglion block was performed with $2 \%$ lidocaine and $98 \%$ ethanol. The patient had significant palliation of the neuropathic pain in her left arm and shoulder.

Sue Cassidy ANP-BC ACHPN, Tina Skrepnik MD, Bree Johnston MD MPH, and Linda Snyder MD

University of Arizona College of Medicine

Departments of Internal Medicine and Radiation Oncology

Tucson, AZ USA

\section{References}

1. Kratz JR, Woodard G, Jablons DM. Management of lung cancer invading the superior sulcus. Thorac Surg Clin. 2017 May;27(2):149-157. [CrossRef] [PubMed]

2. De Leon-Casasola OA. Critical evaluation of chemical neurolysis of the sympathetic axis for cancer pain. Cancer Control. 2000 Mar-Apr;7(2):142-8. [PubMed] 